УДК 621.311.1:519.652

\author{
А. В. Вомошко, Н. Ю. Музика \\ Інститут енергозбереження та енергоменеджменту НТУУ «КПІ» \\ Проспект Перемоги, 37, 03056 Київ, Україна
}

\title{
Прогнозування часових рядів за допомогою іхньої сегментації на основі аналізу вейвлет-скалограм
}

\begin{abstract}
Представлено методологічний підхід при розробчі моделі прогнозування часових рядів, який полягає у застосуванні властивостей частотно-впорядкованих енергій коефіиієнтів ортогонального аналізу за рівнями вейвлет-декомпозииї для виявлення довготривалих трендів, сезонних $і$ шумових компонент. У подальшому проводиться сегментування результатів вейвлет-декомпозииї часового ряду і прогнозування кожного сегмента окремо.
\end{abstract}

Ключові слова: ортогональні перетворення, вейвлет-аналіз, прогнозування, похибка прогнозування.

\section{Вступ}

Короткострокові прогнози електроспоживання (від тижня до доби наперед) $є$ основою для формування диспетчерських графіків (споживання та генерації електроенергії). Узгоджені диспетчерські графіки є найбільш важливими для Об'єднаного ринку електроенергії (ОРЕ) показниками, які визначають основні аспекти його роботи - графіки вироблення електроенергії станціями з урахуванням резервів, склад генеруючого обладнання, об’єми прижбання та продажу електроенергії і потужності на ОРЕ.

На даний час короткострокове прогнозування у ДП «Енергоринок» проводиться за допомогою експертних оцінок та на основі заявок енергопостачальних компаній. У середньому похибка прогнозування складає 1,86 \%, а використання традиційних методів прогнозування і лінійних моделей $-2,85 \%$. При цьому в абсолютних величинах прогноз в окремі години відрізняється від фактичного більше ніж на 1000 МВт.

\section{Анаміз мітературних даних}

На відміну від застосування стандартних методів прогнозування часових рядів (один часовий ряд - один метод прогнозу) [1] останнім часом широкого розвитку набувають два підходи до прогнозування. Підхід 1, який отримав загальну

(C) А. В. Волошко, Н. Ю. Музика 
назву «Pattern recognition» [2] — розпізнавання образів, був запропонований для вирішення задач прогнозування ученим H.R. Folder. У даному підході вперше було запропоновано виконувати прогнозування часових рядів шляхом розбиття процесу прогнозування на два етапи (моделі):

1) виконання процесу кластеризації;

2) прогнозування всередині кожного кластера.

На сьогоднішній день даний підхід до прогнозування є дуже розвиненим і поділяється на два способи підвищення точності прогнозування. Спосіб 1 - це послідовне застосування двох моделей (кластеризація $\longrightarrow$ прогнозування) і спосіб 2 - їхнє паралельне застосування.

Відповідно до способу 1 станом на початок 2015 року найбільш популярними були наступні комбінації моделей: нейронні мережі - нечітка логіка; нейронні мережі - ARIMAX (Autoregressive Integrated Moving Average with Explanatory); нейронні мережі - регресія; нейронні мережі - генетичний алгоритм - нечітка логіка; регресія - нечітка логіка; екстраполяція з вибірки максимальної подоби (EMMSP - extrapolation model on most similar pattern) - ARIMAX [3-8]. Як випливає 3 наведеного вище переліку комбінацій моделей прогнозування, нейронні мережі використовуються як вирішення задач кластеризації, а на другому етапі безпосередньо для прогнозування вибирається той чи інший відомий алгоритм.

Спосіб 2 - так званий консенсус-прогноз (Consensus-forecasting) [9]. Даний спосіб прогнозування також $є$ комбінованим, але на відміну від способу 1 у ньому застосування моделей кластеризації та прогнозування проводиться паралельно. Тобто спочатку прогнозування проводиться різними комбінованими методами (pattern forecasting), а потім при складанні консенсус-прогнозу береться середнє значення отриманих результатів. Застосування даного комбінованого методу прогнозу просто уточнює (усереднює) результати прогнозу. Відповідно до [10] стверджується, що точність консенсус-прогнозу може бути вищою ніж точність кожного із прогнозів окремо.

Подальший розвиток застосування даного підходу до прогнозування часових рядів проходить у плані розвитку (модифікації) методів кластеризації і модифікації відомих статистичних методів прогнозування. До них відносяться: метод довгострокового прогнозування з використанням багатошарової нейронної мережі 3 багатозначними нейронами (MLMVN - Multi-Layer Neural Network with MultiValued Neurons) 3 навчаючим алгоритмом зворотного похідного дерева, гібридні експертні системи прогнозування, впровадження різного роду методів попередньої обробки часового ряду [11-13].

Підсумовуючи результати дослідження сфери застосування нейронних мереж для цілей прогнозування, необхідно відмітити їхні основні недоліки, а саме:

- більшість підходів до проектування штучних нейронних мереж $\epsilon$ евристичними і часто не приводять до однозначного рішення;

- для побудови моделі об'єкта на основі штучних нейронних мереж вимагається виконання багатоциклового налаштування внутрішніх елементів і зв'язків між ними;

- проблеми, які виникають при підготовці навчаючої вибірки, пов'язані 3 труднощами знаходження достатньої кількості навчаючих прикладів;

— навчання мережі у ряді випадків призводять до тупикових ситуацій; 
- тривалі часові затрати на виконання процедури навчання часто не дозволяють застосовувати штучні нейронні мережі в системах реального часу.

Метою даної роботи $є$ вдосконалення (модифікація) підходів «Pattern recognition» та «Consensus-forecasting» у плані підвищення точності прогнозування шляхом вибору оптимального базису ортогонального розкладання часового ряду та застосування відповідних методів прогнозу залежно від структури часового ряду.

\section{Постановка проблеми}

В останні роки в усіх сферах обробки інформаційних сигналів застосовуються їхні ортогональні перетворення, зокрема вейвлет-аналіз [14]. Для побудови математичної моделі прогнозування у даній роботі застосовуються властивості частотно-впорядкованих енергій вейвлет-коефіцієнтів для виявлення довготривалих трендів, сезонних і шумових компонент часового ряду, сегментуванні результатів його ортогональної декомпозиції і подальшого прогнозування кожного сегмента адаптованим до нього методом прогнозування окремо. Наступний синтез результатів прогнозу (зворотне вейвлет-перетворення) і буде результатом прогнозу часового ряду.

Як відомо, скалограма (один з видів компактного зображення розподілу величин вейвлет-коефіцієнтів. Вона являє собою функцію, яка відображатиме інтегральний внесок вейвлет-образу на кожному масштабі) у дискретному вейвлетперетворені аналогічна періодограмі зі спектрального аналізу часових рядів. При цьому, періодограма проводить декомпозицію енергії сигналу відповідно до різноманітних частот Фур'є, а скалограма декомпозує енергію сигналу відповідно до рівнів вейвлет-перетворення [15].

Аналітичне вейвлет-перетворення обчислюється за допомогою аналітичного вейвлету $\Psi$

$$
W f(u, s)=\left\langle f, \Psi_{u, s}\right\rangle=\int_{-\infty}^{+\infty} f(t) 1 / \sqrt{s} \Psi(t-u / s) d t
$$

і визначає локальну частотно-часову щільність енергії $P_{w} f$, яка вимірює енергію сигналу $f$ в прямокутнику Гейзенберга [16] для кожного вейвлету $\Psi_{u, s}$ iз центром у $(u, \xi=u / s)$ :

$$
P_{w} f(u, \xi)=|W f(u, s)|^{2}=|W f(u, u / \xi)|^{2} .
$$

Ця густина енергії і є скалограмою (в деяких джерелах - скейлограма). При цьому необхідно відмітити наступне. Аналітичне перетворення вейвлет-функції $f$ залежить тільки від її аналітичної частини $f_{a}$, і закон зберігання енергії на всіх рівнях вейвлет-перетворення виглядає наступним чином (відповідно до теореми Парсеваля[17]): 


$$
\int_{-\infty}^{+\infty}\left|f_{a}(t)\right|^{2} d t=1 / c_{0} \int_{0}^{+\infty} \int_{-\infty}^{+\infty}\left|W f_{a}(u, s)\right|^{2} d u d s / s^{2}
$$

Дискретне вейвлет-перетворення запишемо наступним чином:

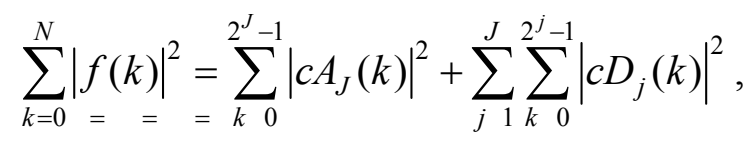

де $\sum_{k=0}^{N}|f(k)|^{2}$ - сумарна енергія дискретизованого сигналу; $N$ - число дискрет на періоді; $\sum_{k=0}^{2^{J}-1}\left|c A_{J}(k)\right|^{2}-$ енергія, яка міститься в апроксимуючих коефіцієнтах останнього (j-го) рівня вейвлет-декомпозиції (у випадку вейвлет-перетворення за алгоритмом Малла); $\sum_{j=1}^{J} \sum_{k=0}^{2^{j}-1}\left|c D_{j}(k)\right|^{2}$ - енергія, яка міститься в деталізуючих коефіцієнтах усіх рівнів вейвлет-декомпозиції - від рівня 1 до рівня $J(\mathrm{E}(1)-\mathrm{E}(J))$.

Скалограма буде представляти собою вектор зі значень енергій на кожному рівні вейвлет-декомпозиції

$$
\left[\left\{c A_{J}^{2}(k)\right\}_{1 \leq k \leq 2^{j}-1}^{2}, \mathrm{E}(1), \mathrm{E}(2), \ldots, \mathrm{E}(J)\right] .
$$

Для проведення дослідження було змодельовано інформаційний сигнал (рис. 1) з наявністю тренду, циклічної компоненти та шуму.

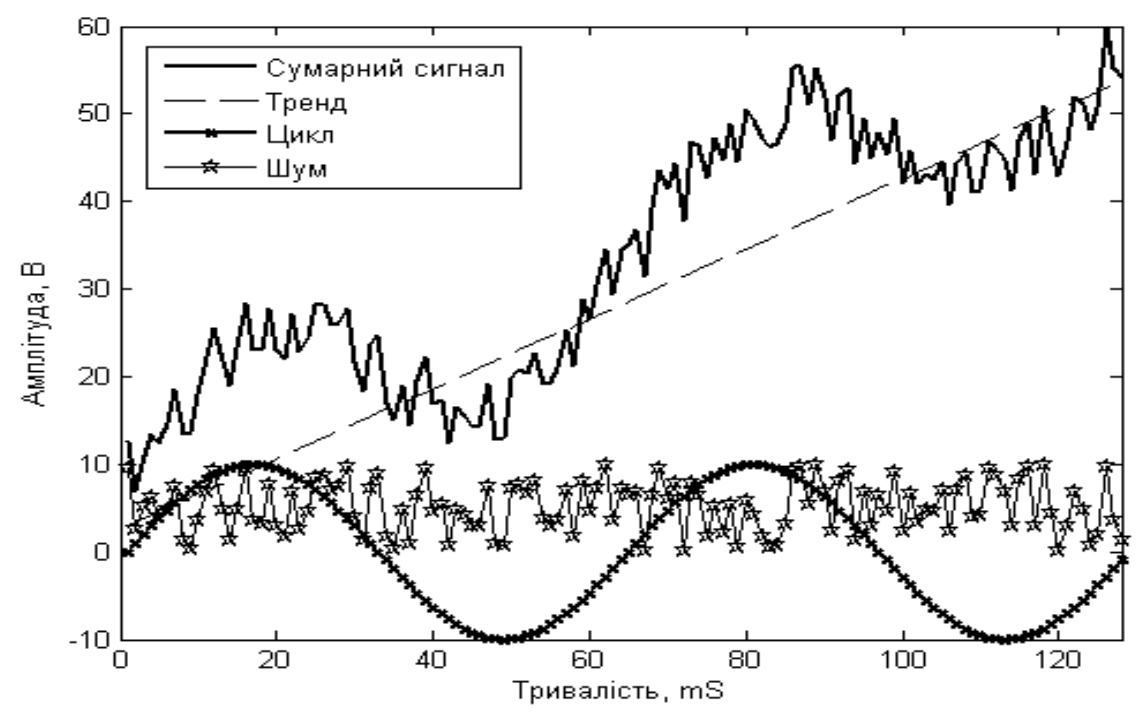

Рис. 1. Змодельований інформаційний сигнал

Відповідно до (4) та (5) розрахуємо та побудуємо скалограму (рис. 2). Для видалення шумової компоненти застосуємо метод виділення шумової компоненти [18]. На рис. 2,б представлено скалограму змодельованого інформаційного сигна- 
лу після видалення шумової компоненти (значення енергії високочастотних рівнів 1-3 дорівнює нулю).

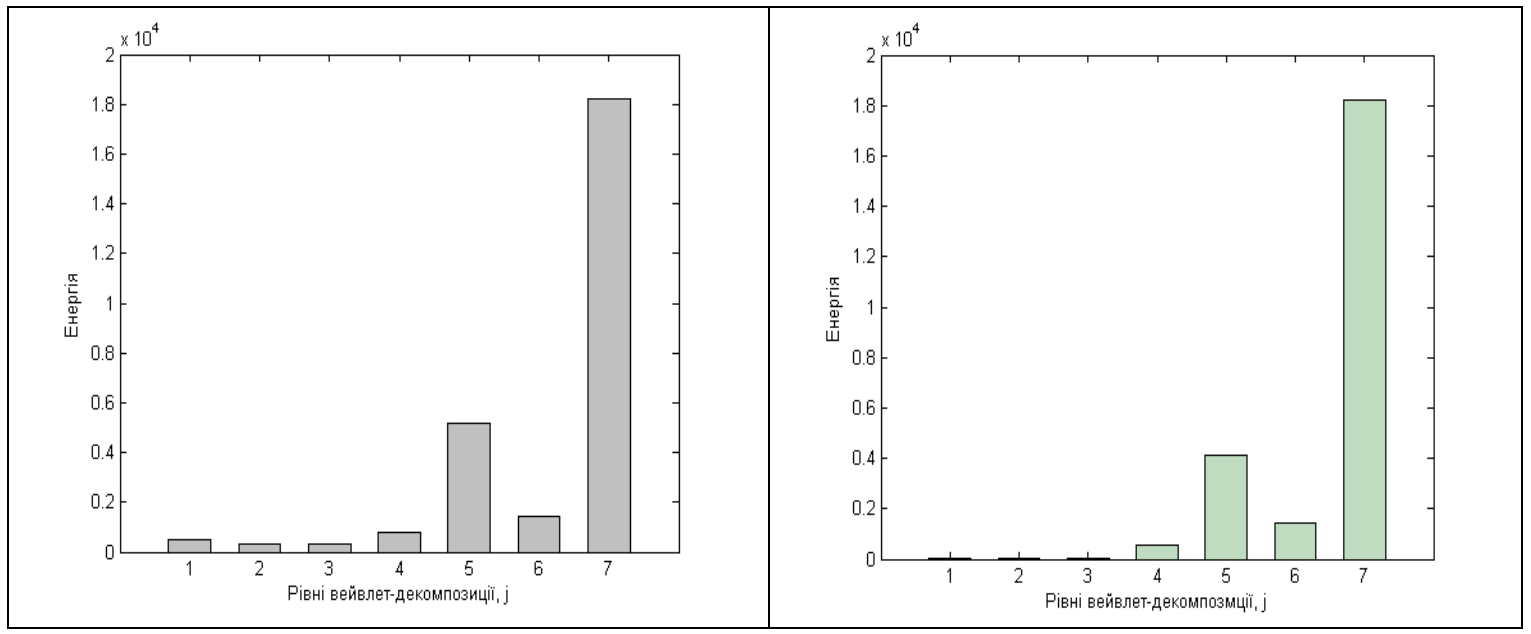

a)

б)

Рис. 2. Скалограма інформаційного сигналу: а) досліджуваного; б) із видаленим шумом

\section{Результати роботи}

Застосування методу прогнозу із рухливим середнім (ARMA) для прогнозування змодельованого на рис. 1 сигналу показало наявність похибки в розмірі 10,46 \%, що є неприйнятним. Тобто виникає необхідність розробки та/або вдосконалення методів підвищення точності прогнозування.

Аналіз скалограми (рис. 2,б) показує наявність двох явно виражених складових (піків). Перша складова охоплює рівні вейвлет-декомпозиції від 4 до 6, а друга - рівень 7. У зв'язку з цим пропонується ідентифікувати дані періодичні компоненти сигналу шляхом їхнього розбиття на дві серії (сегменти) вейвлеткоефіцієнтів $\left\{c D_{j}^{(1)}(k)\right\}=\left\{c D_{j}(k)\right.$ для $j=4-6 \cap 0$ для $j=1-2$, 7, та $\left\{c D_{J}^{(2)}(k)\right\}=\left\{c D_{J}(k)\right.$ для $j=7 \cap 0$ для $j=1, \ldots 6$. При цьому, апроксимуючі вейвлет-коефіцієнти останнього рівня вейвлет-декомпозиції $(j=7)$ представляють собою тренд, а деталізуючі вейвлет-коефіцієнти - сезонну складову.

Прогнозування окремих сегментів (перший методом Тейла-Вейджа, інший - методом ARMA) показало похибку прогнозування - 4,2 \%. Подальший аналіз застосування скалограми до прогнозування проводився шляхом аналізу впливу на точність прогнозування наявності «перетікання» енергії між рівнями вейвлетдекомпозиції. Для цього було змодельовано два сигнали із різними скалограмами (рис. 3, $a$ та 3,б).

Аналіз скалограми (рис. 3,a) показує необхідність розбиття (сегментування) вейвлет-декомпозиції (високо-середньочастотної) на два сегменти: перший — рівні вейвлет-декомпозиції $j=1-3$, другий $-j=4-6$, та низькочастотної $j=7$. У результаті чого отримуємо наступні сегменти, які характеризуються відповідними векторами. 


\section{1. Сегмент 1:}

$$
y^{(1)}=\left\{\begin{array}{l}
\left\{c A_{J}(k)\right\}_{1 \leq k \leq 2^{J}-1}, \\
y^{(2)}=0, \\
y^{(3)}=0 .
\end{array}\right.
$$

2. Сегмент 2:

$$
y^{(2)}=\left\{\begin{array}{l}
y^{(1)}=0, \\
\left\{c D_{j}(k)\right\}_{1 \leq k \leq 2^{j}-1}^{1 \leq j \leq 3}, \\
y^{(3)}=0 .
\end{array}\right.
$$

3. Сегмент 3:

$$
y^{(3)}=\left\{\begin{array}{l}
y^{(1)}=0, \\
y^{(2)}=0, \\
\left\{c D_{j}(k)\right\}_{2^{j}-1 \leq k \leq 2^{6}-1}^{4 \leq j \leq 6} .
\end{array} .\right.
$$

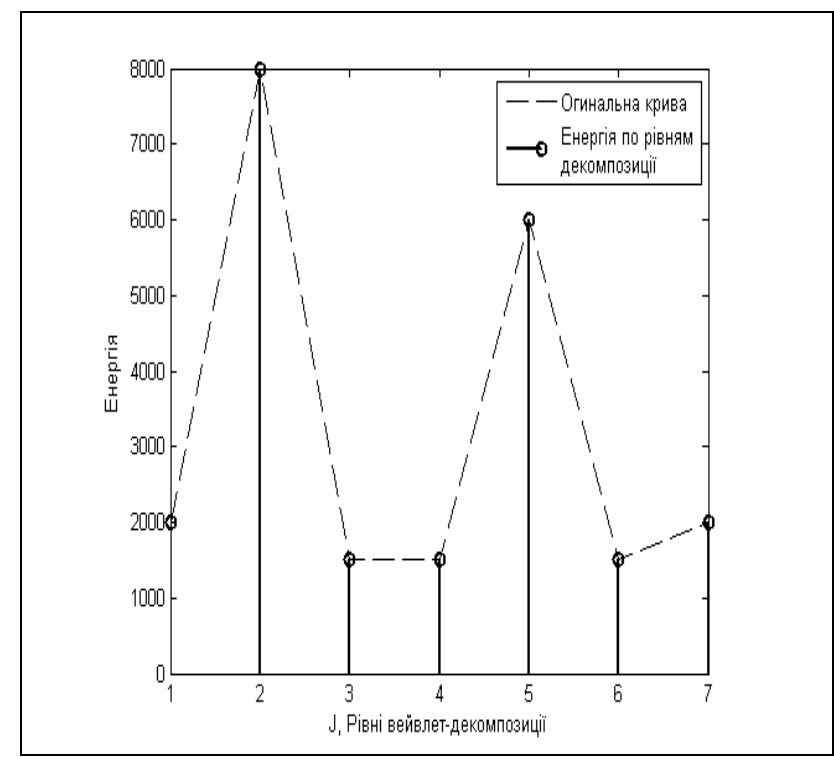

a)

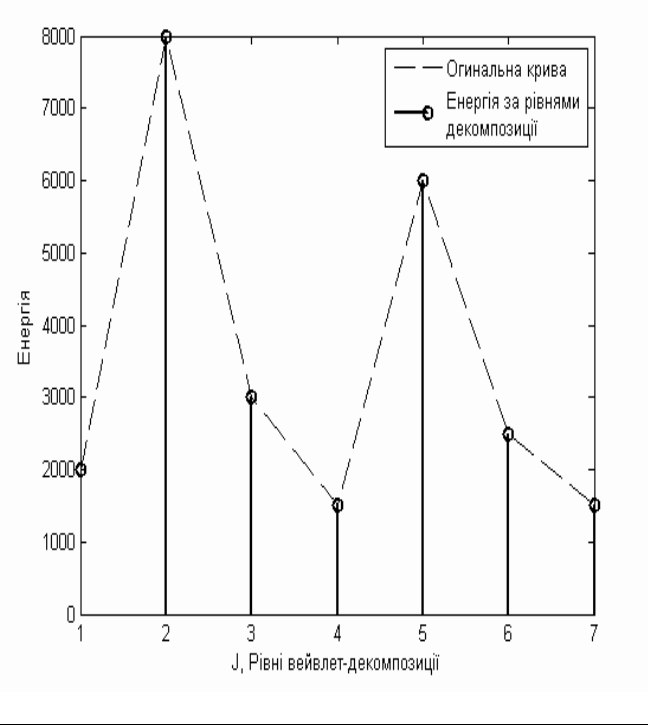

б)

Рис. 3. Змодельовані сигнали з різними скалограмами: а) з наявністю двох яскраво виражених піків; б) з наявністю двох піків із суміжним рівнем вейвлет-декомпозиції (рівень 4)

Подальше прогнозування проводилося за трьома сегментами окремо. Зворотне вейвлет-перетворення спрогнозованих вейвлет-коефіцієнтів кожного сегмента і є зпрогнозованим модельним часовим рядом: 


$$
Y_{1}=W^{-1} \cdot y^{(1)}, Y_{2}=W^{-1} \cdot y^{(2)}, Y_{3}=W^{-1} \cdot y^{(3)},
$$

де $W^{-1}$ - зворотне вейвлет-перетворення;

$$
\hat{Y}=Y_{1}+Y_{2}+Y_{3}
$$

Похибка прогнозування зменшилася на 1,2 \%.

Другий випадок (рис. 3,б) - на скалограмі присутні два піки, але енергія одного рівня вейвлет-декомпозиції є закінченням попереднього піку і початком наступного піку (рівень 4). Аналіз впливу віднесення вейвлет-коефіцієнтів суміжного рівня (рівня 4) до сегмента $(j=1-3)$ та $(j=5-7)$ на точність прогнозування, показав збільшення відносної похибки прогнозування на - 0,6 \% та 1,2 \% відповідно.

Тобто, якщо на скалограмі чітко простежується той факт, що вейвлет-коефіцієнти будь-якого рівня вейвлет-декомпозиції $є$ суміжними декількох сегментів (піків), необхідно проводити додаткові математичні перетворення для зменшення його перехресного впливу на результати прогнозування. А саме, пропонується вирішувати дану проблему наступним чином.

Як відомо, апроксимуючі та деталізуючі вейвлет-коефіцієнти є скалярним добутком інформаційного сигналу зі скейлинг $\varphi(x)$ і масштабуючої (вейвлет) $\psi(x)$ функцій відповідно. А саме $c A_{j, t}=\frac{1}{2^{j}}\left\langle f(x), \varphi\left(\frac{x-t}{2^{j}}\right)\right\rangle$ та $c D_{j . t}=\frac{1}{2^{j}}\left\langle f(x), \psi\left(\frac{x-t}{2^{j}}\right)\right\rangle$. При цьому ці функції пов'язані наступним чином: $\frac{1}{2} \psi\left(\frac{x}{2}\right)=\varphi(x)-\frac{1}{2} \varphi\left(\frac{x}{2}\right)$. Відповідно до вейвлету Хаара апроксимуюча функція дорівнює \pm 1 на всьому інтервалі вейвлет-базису, а деталізуюча - $\pm 1 / 2$. При цьому кожен деталізуючий вейвлеткоефіцієнт $c D_{j, k}$ «породжується» своїм деталізуючим вейвлет-коефіцієнтом рівня $j-1$ кількістю у два рази меншою, тобто $c D_{j-1,[k / 2]}$. У той же час деталізуючий вейвлет-коефіцієнт $c D_{j, k}$ «породжує» два деталізуючих вейвлет-коефіцієнти нижчого рівня $c D_{j+1,2 k}$ та $c D_{j+1,2 k+1}$.

Тобто, деталізуючий вейвлет-коефіцієнт $\left\{c D_{6, k}^{(1)}\right\}$ пропорційний величині коефіцієнтів його породження $[k / 2]$ та середній величині обох породжуваних ним коефіцієнтів рівня $j+1$ [19]. Враховуючи дані властивості деталізуючих вейвлеткоефіцієнтів на суміжному рівні вейвлет-декомпозиції після ряду перетворень запишемо їх наступним чином:

$$
\begin{aligned}
& \left\{c D_{j, k}^{(1)}\right\}_{1 \leq k \leq 2^{j}-1}=\sqrt{\frac{2 c D_{j-1, k / 2}^{2}+\left(c D_{j+1,2 k}^{2}+c D_{j+1,2 k+1}^{2}\right)}{2 c D_{j-1, k}^{2}} c D_{j, k},} \\
& \left\{c D_{j, k}^{(2)}\right\}_{1 \leq k \leq 2^{j}-1}=\sqrt{\frac{\left(c D_{j+1,2 k}^{2}+c D_{j+1,2 k+1}^{2}\right)}{2 c D_{j-1, k / 2}^{2}+\left(c D_{j+1,2 k}^{2}+c D_{j+1,2 k+1}^{2}\right)} c D_{j, k} .}
\end{aligned}
$$


У кінцевому вигляді внесок вейвлет-коефіцієнтів суміжного рівня вейвлетдекомпозиції у відповідні сегменти (враховуючи (11) та (12)) і значення середнього (згідно властивостей апроксимації)) буде представлятись у вигляді:

$$
\left\{c D_{4, k}\right\}^{2}=\left\{c D_{4, k}^{(1)}\right\}^{2}+\left\{c D_{4, k}^{(2)}\right\}^{2} .
$$

Пропонується враховувати внесок суміжного вейвлет-коефіцієнта до складу суміжних сегментів наступним чином. До складу сегмента, який знаходиться зліва від суміжного рівня вейвлет-декомпозиції, - за формулою (11), а справа — за формулою (12). При цьому враховується, що енергія вейвлет-коефіцієнтів суміжного рівня вейвлет-декомпозиції дорівнює сумі енергій значень вейвлет-коефіцієнтів, які відносяться до обох суміжних сегментів (відповідно до (13)). Відносна похибка прогнозування запропонованим методом склала 1,06 \%.

\section{Висновки}

Перш ніж застосовувати ті чи інші методи прогнозу необхідно провести вейвлет-декомпозицію інформаційного сигналу, побудувати скалограму, i на основі результатів іiі аналізу сегментувати коефіцієнти вейвлет-декомпозиції за наступними правилами. У випадку наявності на скалограмі одного піку, проводиться сегментування вейвлет-коефіцієнтів на апроксимуючу та деталізуючу частини, кожна 3 яких підлягає окремому прогнозуванню з використанням відповідного методу. Якщо на скалограмі спостерігається декілька піків - проводиться відповідна ідентифікація періодичних компонент шляхом розбиття вейвлет-коефіцієнтів на окремі серії, за кожною з яких проводиться окреме прогнозування.

Запропоновану модель прогнозування доцільно застосовувати для середньострокового прогнозування інформаційних сигналів, оскільки похибка прогнозу при цьому знаходиться у межах $\pm 1,0 \%$.

1. Бэнн Д.В. Сравнительные модели прогнозирования электрической нагрузки / Д.В. Бэнн, Е.Д. Фармер. - М.: Энергоатомиздат, 1987. - 197 с.

2. Fogler H.P. A pattern recognition model for forecasting / H.P. Fogler // Management science. - 1974. - N 8. - P. 1178-1189.

3. Митюшкин Ю.И. Soft Computing: ідентифікація закономірностей нечіткими базами знань: монографія / Ю.И. Митюшкин, Б.І. Мокін, О.П. Ротштейн. - Вінниця: УНІВЕРСУМ - Вінниця, 2002. - $145 \mathrm{c}$.

4. Santi E. Hybrid ARIMAX-NN model for forecasting Inflation / E. Santi, P.D. Dwi // International Conference on Science, Technology and Humantly. — 2015. — P. 181-187.

5. Bennett G.J. Autoregressive with Exogenous Variables and Neural Network Short-Time Load Forecast Model for Residential Low Voltage Distribution Networks / C. Bennett, R.A.S Stewart, J. Lu // Energies. - 2014. - N 7. - P. 2938-2960.

6. Takagi H. Introduction to Fuzzy Systems, Neural Network and Genetic Algoritms [Електронний ресурс] / Н. Takagi. — Режим доступу: /www.teleametrika.net/reference/Software/infoToFuzzySystemsNeuralNetsGeneticAlgoritms.pdf 
7. Shaible B. Fuzzy Logic based Regression models for Electronics manufacturing Applications [Електронний ресурс] / B. Shaible, Y.C. Lee. - Режим доступу: citeseerx.ist.psu.edu/viewdoc/ download?doi=10.1.1.17.65458\&rep=rep\&type $=$ pdf

8. Чучуева И.А. Модель экстраполяции временных рядов по выборке максимального подобия / И.А. Чучуева // Информационные технологии. - 2010. — № 12. - С. 43-47.

9. Grauder J. Combaining Forecasts Twenty years Later / J. Grauder, W.J. Clive // Journal of Forecasting. - 1989. - Vol. 8. - P. 167-173.

10. Oliva R. Managing Functional Biases Organizational Forecasts: A Case Study of Consensus Forecasting in Supply Chain Planning / R. Oliva, N. Watson // The International Journal of Applied Forecasting. - 2006. - Issue. 5. - P. 27-31.

11. Aizenberg I. Multilayer Neural Network with Multi-Valued Neurons in Time series Forecasting of Oil Production / I. Aizenberg, L.Sheremetov, L. Willa // Springer. — 2011. — 273 p.

12. Bennett G.J. Forecasting low voltage distribution network demand profiles using a pattern recognition based expert sysnem [Електронний pecypc] / G.J. Bennett. - Режим доступу: http://dx.doi.org/10.1016/j.energy.2014.01.032.

13. Paulo M. Modeling and forecasting interval Time Series with Threshold models: An Application to S\&P 500 Index Returns [Електронний ресурс] / M. Paulo, M. Rodrigues, N. Salish. - Режим доступу: http://www.bportugal.pt/e

14. Малла С. Вейвлеты в обработке сигналов: пер. с англ. - М.: Мир, 2005. — 671 с.

15. Волошко А.В. Класифікація інформаційних сигналів за відносною ентропією по рівнях вейвлет-декомпозиції / Енергетика: економіка, технології, екологія. — 2015. — № 3(41). С. $20-27$.

16. Гейзенберг В. Сучасна квантова механіка. Три нобелівських доповіді / В. Гейзенберг, Е. Шредінгер, П.А. Дірак. - М.: ГТТІ. 2004. - С. 13-35.

17. Ghandehari M. A four dimensional continuous wavelet transform. Commutative and Noncommutative Harmonic Analysis and Applications, Contemporary Mathematics / M. Ghandehari, A. Syzdykova, K. Taylor // Amer. Math. Soc., Providence. - 2013. - Vol. 603. — P. 123-136.

18. Волошко A.B. Щодо застосування вейвлет-перетворення для визначення та оцінки показників якості електричної енергії / А.В. Волошко, А.Л. Харчук // Енергетика: економіка, технології, екологія. - 2013. - № 1. - С. 28-34.

19. Arino M.A. Wavelet scalograms and their application in ecjnjmic time series / M.A. Arino, P.A. Morettin, B. Vidakovic // Brazilian Journal of Probability and Statistics. — 2004. — Vol. 18. P. 37-51. 